\title{
Behaviour and time allocation of the mud shrimp, Corophium volutator, during the tidal cycle: a laboratory study
}

\author{
Annelies De Backer $\cdot$ Evy Van Ael $\cdot$ Magda Vincx $\cdot$ \\ Steven Degraer
}

Received: 27 June 2008 / Revised: 3 July 2009 / Accepted: 23 July 2009 / Published online: 5 August 2009

(C) Springer-Verlag and AWI 2009

\begin{abstract}
Despite the numerous ecological and behavioural studies, relatively little is known about the behavioural dynamics of Corophium volutator during the tidal cycle. In the present study, the behaviour of $C$. volutator was observed in the laboratory in a tide-simulated aquarium, and time allocation of the different activities was quantified. Overall, the surface activity was low and showed a steep decline after submersion. A clear tide-based cyclic pattern was found, with a boost of activity immediately after first submersion, continuing during submersion, and shifting over a period with decreasing activity towards almost total inactivity at the end of emersion.
\end{abstract}

Keywords Amphipoda Corophium volutator . Behaviour · Time allocation

Communicated by H.-D. Franke.

A. De Backer $(\bowtie) \cdot$ E. Van Ael $\cdot$ M. Vincx $\cdot$ S. Degraer Biology Department, Marine Biology, Ghent University, Campus Sterre, Krijgslaan 281-S8, 9000 Ghent, Belgium e-mail: annelies.debacker@ilvo.vlaanderen.be

Present Address:

A. De Backer

Institute for Agriculture and Fisheries Research,

Ankerstraat 1, 8400 Oostende, Belgium

S. Degraer

Management Unit of the North Sea Mathematical Models, Royal Belgian Institute of Natural Sciences, Gulledelle 100, 1200 Brussels, Belgium

\section{Introduction}

Corophium volutator (Crustacea, Amphipoda) is an abundant species on many mudflats worldwide. Population densities frequently reach $>20,000$ ind. $\mathrm{m}^{-2}$, and in summer months densities can locally exceed 100,000 ind. $\mathrm{m}^{-2}$ (Gerdol and Hughes 1994). The high population densities make this amphipod an important species in many mudflat ecosystems, where it is a significant prey for migratory shorebirds and juvenile flounders (Boates et al. 1995). Corophium volutator lives in U-shaped burrows in the upper $5 \mathrm{~cm}$ of the sediment. It is known to switch between surface deposit feeding and filter feeding depending on the phytoplankton concentration in the water column (Riisgård and Schotge 2007). However, relatively little is known about the behavioural dynamics of $C$. volutator throughout the tidal cycle. Therefore, this study aims to quantify the time allocation of the amphipod activities during a simulated tidal cycle.

\section{Materials and methods}

Experimental setup

To quantify the time allocation of the full spectrum of activities of C. volutator, it was necessary to perform both surface and subsurface observations. Since it was, however, impossible to conduct simultaneous observations of both the surface and subsurface activities of $C$. volutator, a surface and a subsurface survey were performed in parallel. The experimental setup comprised a main aquarium (L: $50 \mathrm{~cm} \times \mathrm{W}: 10 \mathrm{~cm} \times \mathrm{H}: 15 \mathrm{~cm}$ ) used for surface and subsurface (animals against the glass wall) observations and a thin aquarium (L: $30 \mathrm{~cm} \times \mathrm{W}: 3 \mathrm{~mm} \times \mathrm{H}: 15 \mathrm{~cm})$ for 
Table 1 Description of the different activities observed under laboratory conditions

\begin{tabular}{|c|c|}
\hline Activity & Description \\
\hline \multicolumn{2}{|l|}{ Surface activity } \\
\hline Surface inactivity & No visible forward/backward movement \\
\hline Surface crawling & $\begin{array}{l}\text { The animal pushes itself forward with telson, uropods, second antennae, } \\
\text { and pereopods }\end{array}$ \\
\hline Swimming & Mostly done vertical, and resulting from fast beating of the pleopods \\
\hline Scraping & $\begin{array}{l}\text { Surface deposit feeding: second antennae are used to scrape surface sediment } \\
\text { with microphytobenthos into the burrow }\end{array}$ \\
\hline Flushing (undescribed previously) & $\begin{array}{l}\text { The pleopods create a faster water movement to get rid of excess sand grains } \\
\text { and faeces from the burrow. Visible on the surface as a dust cloud }\end{array}$ \\
\hline \multicolumn{2}{|l|}{ Subsurface activity } \\
\hline Subsurface inactivity & No visible motion, Corophium is completely in rest \\
\hline Ventilating \& filter feeding & $\begin{array}{l}\text { Beating pleopods create water current through the burrow (ventilation) } \\
\text { and both gnathopods and mouthparts process the sand grains. Ventilation } \\
\text { and feeding do not necessarily occur at the same time }\end{array}$ \\
\hline Subsurface walking & Walking up and down in the burrow \\
\hline Bulldozing & Pushing excess sand grains out of the burrow with the pleon \\
\hline
\end{tabular}

Mainly based on Meadows and Reid (1966)

subsurface observations. Both aquaria were placed in a temperature controlled room $\left(15^{\circ} \mathrm{C}\right)$ with a $12: 12 \mathrm{~h}$ light:dark regime and we simulated a tidal cycle of about $12 \mathrm{~h}$. The experimental tidal regime was similar to the natural tidal conditions of the $C$. volutator habitat: $3 \mathrm{~h}$ of submersion, followed by $9 \mathrm{~h}$ of emersion.

The sediment and the animals were collected in January 2005 from a mudflat-saltmarsh area in Nieuwpoort (Belgium, $51^{\circ} 08^{\prime} \mathrm{N}, 2^{\circ} 44^{\prime} \mathrm{E}$ ). After defaunation by freezing-thawing, the sediment was allowed to settle in the aquaria for $24 \mathrm{~h}$, before the amphipods were added. The test population reflected the natural composition, with a highly skewed sex ratio of one male to six females. In both aquaria, $C$. volutator was introduced at a density of 10,000 ind. $\mathrm{m}^{-2} \quad$ (average field density $=10,762$ ind. $\left.\mathrm{m}^{-2} \pm \mathrm{SE} 406\right)$. Observations started 3 days after incubation of the animals. The test specimens were weekly fed ad libitum with benthic diatoms (Navicula sp.).

\section{Observations}

Based on the preliminary observations nine behavioural activities were defined (Table 1). The tidal cycle was divided into 12 1-h observation periods (i.e. $3 \mathrm{~h}$ of observation when submersed and $9 \mathrm{~h}$ when emersed). Each observation period was replicated five times during the length of the experiment. Observations were done during a 3-week period with a maximum of five observation hours per day and a maximum of two successive observation hours to exclude biases due to fatigue of the observer. This implies that some animals were possibly observed more than once on consecutive days, especially for subsurface observations where the number of observed animals was limited. Owing to practical constraints, observations were done during daylight.

During each observation period, approximately ten surface active or subsurface individuals were randomly selected for a detailed quantification of their surface or subsurface time allocation over a 5-min period. Their activities were recorded on a dictaphone. During a surface activity survey only surface activities (Table 1) were taken into account and vice versa for subsurface activity surveys. Because subsurface observations were complicated by logistic problems, more surface activity observations were made. The time expenditure for the different activities of each surveyed individual was converted to percentages (i.e. time allocation).

Integrating surface and subsurface time allocation patterns

Each observation period started and ended with a surface scan to determine the relative abundance of surface active animals. The average of both surface scan measurements allowed to quantify the average importance of surface activity relative to subsurface activity during a given observation period. These values were then used to rescale the observed time allocation of both the surface and subsurface surveys. If, for example, on average $6 \%$ of the individuals in the experimental setup were observed to be surface active $1 \mathrm{~h}$ after flooding and only $4 \% 1 \mathrm{~h}$ later, then the time allocation of all surface activities between 1 and $2 \mathrm{~h}$ after flooding were rescaled to $5 \%$, while the time allocation of all subsurface activities were rescaled to $95 \%$. 
Fig. 1 Behavioural pattern and time allocation of $C$. volutator throughout the simulated tidal cycle. Thick dotted line indicates average percentage of surface active individuals (obtained from surface scan). Below dotted line: rescaled time allocation of surface activities. Above dotted line: rescaled time allocation of subsurface activities

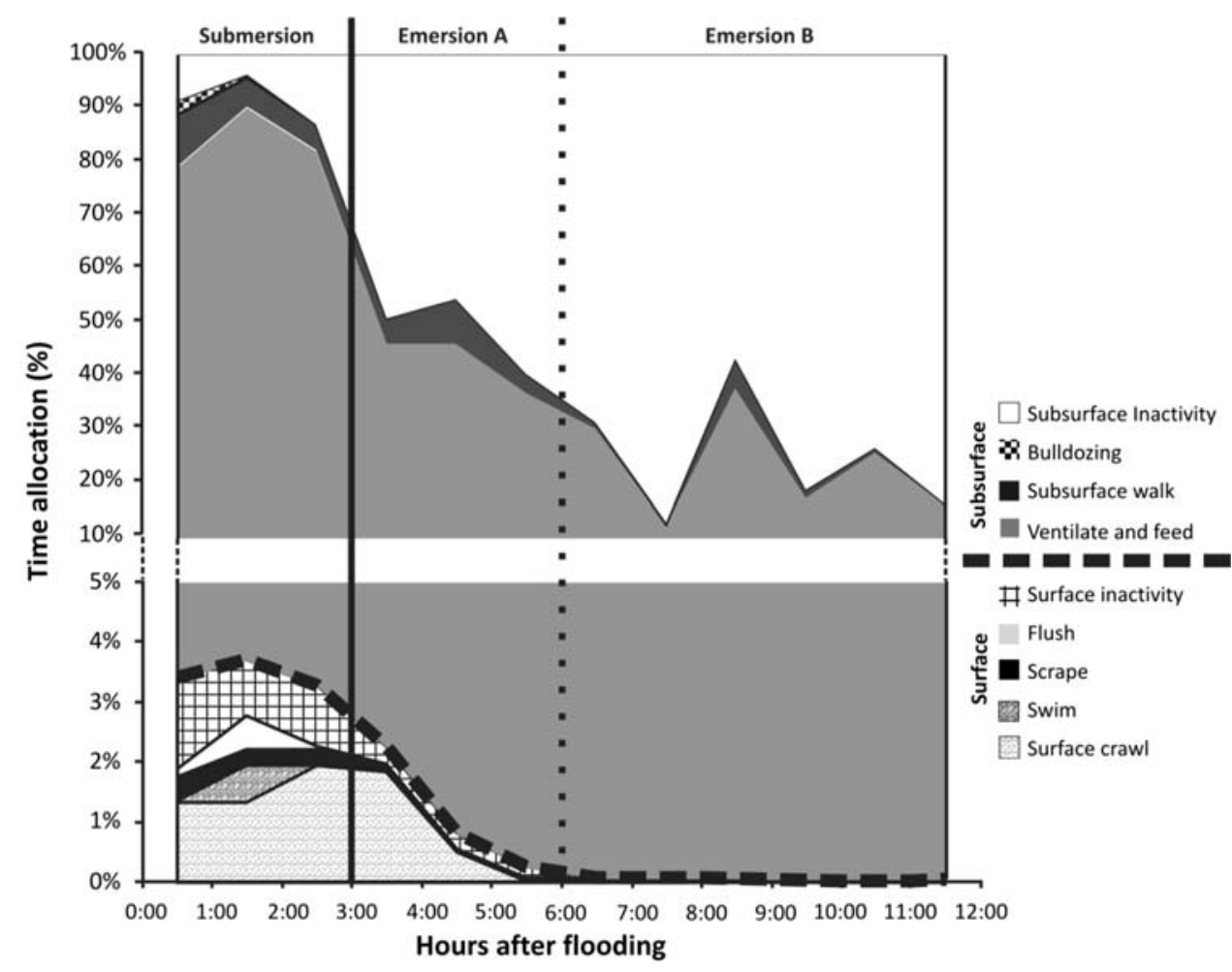

Data analysis

All analyses were done using time allocation data. To achieve homogeneity of variance, data were arcsine transformed. Some data could not be corrected for heteroscedasticity. In these cases, untransformed data were analysed, since ANOVA is considered robust to lack of homogeneity when sample sizes are large, as is the case here (Underwood 1997). Furthermore, the large sample size allows the statistics to follow a normal distribution (central limit theorem) (Sokal and Rohlf 1981). Significant differences were based on $P<0.05$. When significant, Tukey's HSD post hoc testing was applied.

\section{Results}

Surface counts of active individuals at the start of each observation period showed that surface activity rapidly decreased after emersion to $0.1 \%( \pm$ SD $0.1 \%) 3 \mathrm{~h}$ after emersion. Even during submersion, the total proportion of surface active individuals was low with maximum of $3.7 \%$ (Fig. 1). A significant difference in surface activity was found between submersion and emersion ( $t$ test: $t$ value $=7.48, d f=58, P<0.0001)$. Some activities were observed frequently, but lasted shortly (e.g. scraping, subsurface walk), while others were longlasting in comparison with the frequency of occurrence (e.g. subsurface inactivity) (Table 2). During the surveys for surface activity, the animals spent $\geq 80 \%$ of the time subsurface and especially during emersion often no animals were active on the surface. Over $90 \%$ of the subsurface time was spent with ventilating and filter feeding $(44 \%)$ and being inactive $(51 \%)$ (Table 2).

Although variability amongst the observations of the different individuals was high, clear patterns could be distinguished. Visual exploration of time allocation data allowed to distinguish three periods in the tidal cycle: a period of submersion (0-3 h after flooding), emersion $\mathrm{A}$ (3-6 $\mathrm{h}$ after flooding) and emersion B (6-12 h after flooding) (Fig. 1). This distinction was confirmed statistically by a one-way ANOVA with 'hours after flooding' as independent variable and the activities as dependent variables. All observed activities, except subsurface walking, differed significantly between the submersion period and both emersion periods. During submersion, the diversity of activities and the overall activity was highest, while consequently the subsurface inactivity was low (4-13\%). Swimming, flushing and bulldozing only occurred during submersion (Fig. 1).

For the majority of activities during emersion (except scraping), significant differences were found between the first $3 \mathrm{~h}$ of emersion (emersion $\mathrm{A}$ ) and the last hours of emersion (emersion B). Emersion A can be seen as a transition period between submersion and emersion $\mathrm{B}$, in which the activity level dropped and (subsurface) inactivity showed a steep increase from 13 to 60\%. During emersion $\mathrm{B}$ (subsurface) inactivity showed a further increase towards 
Table 2 Frequency of occurrence, total time allocation, and average duration of activities, separated for surface and subsurface observations

\begin{tabular}{|c|c|c|c|c|}
\hline & Activity & $\begin{array}{l}\text { Frequency of occurrence }(\%) \\
(n=\text { ind. where behaviour was observed) }\end{array}$ & $\begin{array}{l}\text { Total time } \\
\text { spent }(\%)\end{array}$ & $\begin{array}{l}\text { Average } \\
\text { duration } \pm \mathrm{SD}(\mathrm{s})\end{array}$ \\
\hline \multirow{6}{*}{$\begin{array}{l}\text { Surface survey } \\
\quad(\text { total } n=443)\end{array}$} & Invisible & $62.5(n=417)$ & 86.9 & $276 \pm 62$ \\
\hline & Surface inactivity & $6.4(n=43)$ & 3.9 & $119 \pm 91$ \\
\hline & Surface crawl & $10.2(n=68)$ & 6.6 & $128 \pm 81$ \\
\hline & Swim & $1.3(n=9)$ & 0.8 & $120 \pm 141$ \\
\hline & Scrape & $16.0(n=107)$ & 1.3 & $16 \pm 15$ \\
\hline & Flush & $3.4(n=23)$ & 0.6 & $22 \pm 21$ \\
\hline \multirow{4}{*}{$\begin{array}{l}\text { Subsurface survey } \\
\quad \text { (total } n=152)\end{array}$} & Subsurface inactivity & $37.4(n=108)$ & 51.4 & $217 \pm 105$ \\
\hline & Ventilate and filter feed & $33.6(n=97)$ & 43.8 & $206 \pm 103$ \\
\hline & Subsurface walk & $27(n=78)$ & 4.4 & $26 \pm 25$ \\
\hline & Bulldoze & $2.1(n=6)$ & 0.4 & $34 \pm 22$ \\
\hline
\end{tabular}

$88 \%$, and only three activities (i.e. scraping, ventilating and feeding and subsurface walking) remained (Fig. 1). Scraping was the only activity that continued at more or less the same frequency during the whole emersion period.

\section{Discussion}

Surface activity showed a steep decline the first hours after emersion. During a field study, Lawrie and Raffaelli (1998) found similar results and explained this decline by the drying of the sediment. Another plausible explanation is the increasing risk of predation by shorebirds when the tide is receding (Boates et al. 1995). However, the population used in this experiment is not heavily predated under natural conditions (Devos and De Groote 2006), plus predation was absent in this experiment and $C$. volutator shows flexible surface crawling behaviour in relation to predation risk (Boates et al. 1995). Hence, in this case, the drying of the sediment is the most likely reason for the observed decrease in surface activity. Even during submersion, the number of surface active individuals was very low compared with the one in the sediment and was on average restricted to maximum $3.7 \%$ of the population. When animals were active on the surface, crawling was the dominant activity. Surface crawling can increase seasonally, since (large) males crawl around in search of a female (Meadows and Reid 1966; Lawrie and Raffaelli 1998). Since, the experiment was done in January, no clear indications of reproductive behaviour were seen, but amphipods (both male and female) searching for another burrow during crawling were observed, as described in Meadows and Reid (1966). As reported in other studies, swimming frequency was low and variable patterns were observed in swimming activity with peaks during periods of submersion (Lawrie and Raffaelli 1998).

The behaviour of Corophium showed a cyclic pattern following the simulated tidal cycle with a boost of activity immediately after flooding, continuing during submersion, and shifting over a period with decreasing activity (emersion A) towards almost total inactivity at the end of emersion (emersion B). Although the length of the different activity periods may vary due to seasonal differences (e.g. temperature, light conditions or phytoplankton concentration) or due to different submersion/emersion times depending on the origin of the population a similar cyclic pattern in which these three different periods can be distinguished is to be expected.

It is known that $C$. volutator can switch between feeding modes and that filter feeding is common when phytoplankton concentrations are above a certain trigger level (Riisgård and Schotge 2007). However, the amount of time spent on different feeding modes is unknown and may greatly vary seasonally and geographically (Riisgård and Schotge 2007) depending on the degree of down-mixing of phytoplankton, which is controlled by currents and wind mixing (Riisgård et al. 2007). In the present study, the food offered consisted of benthic diatoms, and the used sea water was filtered, so phytoplankton concentrations were probably below the trigger level and surface deposit feeding was the main feeding mode. Nevertheless, filter feeding was observed as well, in co-occurrence with burrow ventilation, but since it was difficult to make a distinction between both with the naked eye, they were described as a single activity. However, due to the lack of phytoplankton, an underestimation of filter feeding during submersion is possible.

We observed that some individuals were deposit feeding at all stages of the tidal cycle, just as Gerdol and Hughes (1994) concluded from chlorophyll a concentrations of the gut content. However, unlike them, we found a relation between stage of the tide and surface deposit feeding (=scraping), with a higher frequency of scraping during submersion. To conclude, $C$. volutator showed a tidal pattern of behavioural activities with a relatively high rate of 
activity during submersion and a very high rate of inactivity during emersion.

Acknowledgments We would like to thank the editor and the reviewers for their useful comments and suggestions that helped to improve this manuscript. The first author acknowledges a research assistant grant from Ghent University (UGent). This research was financed through the FWO-Vlaanderen project KISS (contract no. G.0480.05) and the Ghent University BBSea project (contract no. GOA 01G00705).

\section{References}

Boates JS, Forbes M, Zinck M, McNeil N (1995) Male amphipods (Corophium volutator [Pallas]) show flexible behaviour in relation to risk of predation by sandpipers. Ecoscience 2(2):123-128

Devos K, De Groote D (2006) Biologische responsvariabelen: avifauna. In: Hoffmann M, Herrier JL, Leten M, Van Nieuwenhuyse H (Survey) Monitoring natuurherstel ijzermonding 2001-2005, p. 386
Gerdol V, Hughes RG (1994) Feeding behaviour and diet of Corophium volutator in an estuary in southeastern England. Mar Ecol Prog Ser 114:103-108

Lawrie SM, Raffaelli DG (1998) Activity and mobility of Corophium volutator: a field study. Mar Freshw Behav Physiol 31:39-53

Meadows PS, Reid A (1966) The behaviour of Corophium volutator (Crustacea: Amphipoda). J Zool 150:387-399

Riisgård HU, Schotge P (2007) Surface deposit feeding versus filter feeding in the amphipod Corophium volutator. Mar Biol Res 3:421-427

Riisgård HU, Lassen J, Kortegaard M, Møller LF, Friedrichs M, Jensen MH, Larsen PS (2007) Filter-feeding zoobenthos and importance of hydrodynamics in the shallow Odense Fjord (Denmark): earlier and recent studies, perspectives and modeling. Estuar Coast Shelf Sci 75:281-295

Sokal RR, Rohlf JF (1981) Biometry: the principles and practice of statistics in biological research. Freeman and Co., San Francisco, pp 131-133

Underwood AJ (1997) Experiments in ecology: their logical design and interpretation using analysis of variance. Cambridge University Press, Cambridge, pp 504 